\title{
Os movimentos indígena e ambientalista sob o viés de análise da História Ambiental: a repercussão no ensino de história
}

\section{The indigenous and environmentalist movements under the Environmental History analysis perspective: the repercussion in history teaching.}

Poliene Soares dos Santos Bicalho* Maria de Fátima Oliveira** Fernanda Alves da Silva Oliveira****

Resumo: Este artigo tem por objetivo analisar a relação entre o Movimento Indígena no Brasil e o movimento ambientalista, a partir das contribuições teórico-metodológicas da História Ambiental. Em um primeiro momento, a abordagem desta problemática perpassa os discursos e ações que aproximam os movimentos indígena e ambientalista, em torno das diversas e questionáveis formas de apropriações de terras indígenas, e o desequilíbrio ecológico causado ao meio ambiente nos últimos cinquenta anos, mais especificamente após o Golpe Militar de 1964, data simbólica para esta questão. Em um segundo momento, buscou-se compreender como os problemas ambientais que incidem diretamente sobre as populações indígenas são tratados nos livros didáticos e na escola como um todo, além de procurar entender como têm sido construídos os discursos dos livros didáticos sobre a temática da preservação do meio ambiente, ou seja, como a Educação Ambiental tem sido abordada nas escolas, tendo como foco de análise as terras indígenas.

Palavras chave: Movimento Indígena, Movimento Ambientalista, Ensino de História.

\footnotetext{
* Doutora em História Social pela Universidade de Brasília (UnB). Pós-Doutorado em Antropologia (PPGAS/UnB). Professora do curso de História da Universidade Estadual de Goiás e do Programa de Pós-Graduação Stricto Sensu Territórios e Expressões Culturais no Cerrado (TECCER/UEG).

** Doutora em História pela Universidade Federal de Goiás (UFG). Docente do curso de Licenciatura em História e do Programa de Pós-Graduação Stricto Sensu Territórios e Expressões Culturais no Cerrado (TECCER).

*** Mestre em Ciências Sociais e Humanidades pelo Programa de Pós-Graduação Stricto Sensu Territórios e Expressões Culturais no Cerrado da Universidade Estadual de Goiás (TECCER/UEG). Professora do Ensino Fundamental da Secretaria Municipal de Educação e Cultura de Nova Mutum (MT)
} 
Abstract: This article aims to analyze the relationship between the Indigenous Movement in Brazil and the environmentalist movement, from the theoretical and methodological contributions of environmental History. At first, the approach to this problem permeates the speeches and actions which bring together environmental and Indigenous movements around the many questionable ways of Indigenous lands appropriation and the ecological imbalance caused in the last fifty years, specifically after the military coup of 1964, which is the symbolic date for this issue. Secondly, we sought to understand how environmental issues which directly affect the Indigenous populations are treated in textbooks and school as a whole. Beyond that, we try to understand how the textbooks' speeches about environmental preservation have been constructed, how the environmental education has been approached in schools focusing on the analysis of Indigenous lands.

Key-words: Indigenous Movement, Environmentalist Movement, History Teaching.

\title{
História Ambiental e os Novos Movimentos Sociais
}

\author{
...quando a floresta acabar e as \\ entranhas da terra tiverem sido \\ completamente destroçadas pelas \\ máquinas devoradoras de minério, as \\ fundações do cosmo ruirão e o céu \\ desabará terrível sobre todos os \\ viventes. Isso já aconteceu antes, \\ lembra o narrador. O que é o modo \\ índio de dizer que acontecerá de novo. \\ (Eduardo Viveiros de Castro, Prefácio da \\ obra A queda do Céu. Palavras de um \\ xamã yanomami, de Davi Kopenawa e \\ Bruce Albert 2015, p.14-15).
}

A inquietação que norteia este artigo se resume no seguinte questionamento: como os problemas ambientais que incidem diretamente sobre as populações indígenas são tratados nos livros didáticos e na escola como um todo? As respostas possíveis ao problema anunciado amparam-se nas contribuições teórico-metodológicas da História Ambiental, que são pertinentes por, entre outros motivos, ater-se às condições da natureza; ao domínio socioeconômico interagindo com o meio ambiente; e às expressões e 
representações sociais e culturais relacionadas ao espaço natural (FRANCO, 2011). Para tanto, destaca-se que uma das contribuições da História Ambiental repousa na tentativa de "tornar a disciplina da história muito mais inclusiva nas suas narrativas do que ela tem tradicionalmente sido" (WORSTER, 1991, p.199).

Nesta perspectiva, Donald Worster (1991, p. 199) ressalta que a História Ambiental "rejeita a premissa convencional de que a experiência humana se desenvolve sem restrições naturais, de que os humanos são uma espécie distinta e 'supernatural', de que as consequências ecológicas de seus feitos passados podem ser ignoradas”. O teórico indígena Ailton Krenak, em Ideias para adiar o fim do mundo, reforça esse olhar nos seguintes termos:

\begin{abstract}
A conclusão ou compreensão de que estamos vivendo uma era que pode ser identificada como Antropoceno deveria soar como um alarme nas nossas cabeças. Porque, se nós imprimimos no planeta Terra uma marca tão pesada que até caracteriza uma era, que pode permanecer mesmo depois de já não estarmos aqui, pois estamos exaurindo as fontes da vida que nos possibilitaram prosperar e sentir que estávamos em casa, sentir até, em alguns períodos, que tínhamos uma casa comum que podia ser cuidada por todos, é por estarmos mais uma vez diante do dilema a que já aludi: excluímos da vida, localmente, as formas de organização que não estão integradas ao mundo da mercadoria, pondo em risco todas as outras formas de viver pelo menos as que fomos animados a pensar como possíveis, em que havia corresponsabilidade com os lugares onde vivemos e o respeito pelo direito à vida dos seres, e não só dessa abstração que nos permitimos construir como uma humanidade, que exclui todas as outras e todos os outros seres. Essa humanidade que não reconhece que aquele rio que está em coma é também o nosso avô, que a montanha explorada em algum lugar da África ou da América do Sul e transformada em mercadoria em algum outro lugar é também o avô, a avó, a mãe, o irmão de alguma constelação de seres que querem continuar compartilhando a vida nessa casa comum que chamamos Terra. (KRENAK, 2019, p. 46-48)
\end{abstract}

A história recente vem reforçando esta assertiva, já que a cada ano a natureza apresenta sinais claros de desequilíbrio ecológico e ambiental causados por desmatamentos, mau uso dos solos, apropriação indevida das matas de galeria e ciliar, crescimento populacional desordenado, hiperconsumo industrial etc. A emergência destas novas vertentes de análise despertou nos historiadores e cientistas sociais outros campos de interesse, assim, "Os historiadores, ao se aproximarem e se preocuparem com as lutas e conflitos vividos no tempo 
presente, passaram a rever e a reconsiderar o lugar da natureza no viver social. Surge, assim, a história ambiental" (BITTENCOURT, 2003, p. 40).

A história, desde muito cedo, apreendeu a natureza como parte do escopo de investigação, haja vista os trabalhos realizados por historiadores ligados ao grupo dos Annales, como Marc Bloch, Lucien Febvre e Fernand Braudel. No Brasil, podemos mencionar as contribuições de Sérgio Buarque de Holanda, em Visões do Paraíso (2010), que abordou temas ambientais muito antes desta área se constituir como um campo específico do conhecimento; Paulo Bertran, em História da Terra e do Homem no Brasil Central (2000); entre outros.

Foi a partir de 1970 que a História Ambiental ganhou fôlego e se fortaleceu no cenário acadêmico, principalmente com a ampliação dos discursos mundiais em torno das questões ambientais e da necessidade de preservar a natureza, pois a mesma clamava (clama) por socorro diante de políticas desenvolvimentistas cada vez mais agressivas e descomprometidas com o meio ambiente. É nesse contexto que os movimentos da sociedade civil organizada se consolidaram em torno das problemáticas sociais e ambientais, através das lutas e movimentos de grupos ambientalistas ou ecológicos.

Com a ampliação dos debates ambientalistas e as amplas mobilizações sociais contra as mazelas e desmandos da Ditadura Militar (1964-1985), a História Ambiental brasileira foi adquirindo espaço e lugares próprios de fala. A implantação da política desenvolvimentista dos Anos JK e sua consequente consolidação no período da Ditadura alavancaram a economia do país à custa de grandes perdas para as populações marginalizadas e desfavorecidas, lembrando que nesse grupo estão os povos indígenas, que tiveram suas terras invadidas, quando não roubadas. No entanto, antes de 1970, os debates em torno destes problemas, elaborados pela púbere História Ambiental daqueles anos, foram cerceados temporariamente.

[...] existe uma interrupção significativa sobre os problemas ambientais entre os anos 1950 e 1970 provocada pelas políticas econômicas criadoras da ideologia do "desenvolvimentismo" que bloqueava questionamentos sobre os impactos ambientais no processo de industrialização em curso no país e demais formas de exploração dos recursos naturais, incluindo os minérios. O surgimento de pesquisas propriamente de história ambiental foi mais tardio, ocorrendo a partir dos anos 80, 
período da denominada "democratização" do país (BITTENCOURT, 2003, p. 48).

Desde os anos de 1980 a História Ambiental vem ampliando as suas produções e contribuições, com abordagens realizadas em vários campos do conhecimento: Ecologia, Biologia, Geografia, Literatura, História etc. Nos estudos históricos, a História Ambiental evidencia um fato interessante, que é, de acordo com Martinez (2006, p. 21), "a vasta experiência de diálogo e de trabalho interdisciplinar que facilita suas aproximações no estudo das relações do ser humano com a natureza no passado", e isso, contribui, sem dúvida, para a construção de uma visão mais crítica e abrangente do presente.

Ao longo desta década passou-se a falar nos Novos Movimentos Sociais (NMSs) que, para além dos movimentos operários e das lutas políticas (sem excluí-las), privilegiaram "a emergência de novos sujeitos sociais e de novas práticas de mobilização social” (SANTOS, 2005, p. 256). Tratava-se, na verdade, de movimentos sociais populares urbanos, que se vincularam a instituições civis já estabelecidas, como a Igreja Católica, por exemplo. Os sujeitos sociais passaram a atuar em diferentes espaços públicos, como a mídia e demais meios de comunicação. Sua prática se definiu pela ação coletiva e individual quanto à forma de lidar com temas atuais, como: preservação do meio ambiente, antimilitarismo, cidadania, direitos humanos etc.

Os NMSs distinguem-se dos modelos clássicos também por apresentar caráter autônomo perante o Estado e os partidos políticos, e por formarem outros grupos organizados através de movimentos sociais, como o movimento negro, de mulheres, ecológicos e dos índios. De acordo com Gohn (1997, p. 283), "O novo nos movimentos ecológicos, das mulheres, etc. referia-se a outra ordem de demanda, relativa aos direitos sociais modernos, que apelavam para a igualdade e a liberdade, em termos das relações de raça, gênero e sexo". E segundo o autor,

As mudanças trazidas pelas inovações econômicas, sociais e políticas dos anos 1990 - neoliberalismo; derrocada do socialismo; fim da bipolaridade; globalização; novas tecnologias - contribuíram para o fortalecimento dos movimentos que apresentaram características locais, mas que alcançaram posições de importância global, como foi e é o caso dos movimentos indígenas e ambientalistas. A luta pela manutenção da cultura indígena fortaleceu muitíssimo o Movimento no 
período, assim como os movimentos "ecológicos, pela paz, direitos humanos, etc.” (GOHN, 1997, p. 239).

Algumas mudanças foram percebidas na organização, prática e discussões teóricas dos movimentos sociais a partir da década de 1990. No Brasil, e em grande parte dos países latino-americanos, as transformações trazidas pela Globalização repercutiram e alteraram as condições da produção e a organização dos novos atores sociais. Nessa perspectiva, compartilha-se a ideia apresentada por Sérgio Leitão quanto à atuação dos novos atores sociais em redes de movimentos sociais, ambientalistas e de gênero. Tais redes se cruzam e entrecruzam a partir da década de 1980 no Brasil, como corolário de acontecimento similar ocorrido nos Estados Unidos e na Europa há cerca de duas décadas.

O processo Constituinte de 1988 foi uma união de forças da sociedade civil. Ali se uniram índios, o movimento ambientalista (que naquele momento começava a despontar), o movimento de luta pela reforma agrária, movimento das mulheres, entre outros que contribuíram para que tivéssemos uma Constituição bastante positiva do ponto de vista dos novos direitos sociais (LEITÃO, 2004, p. 60).

É de conhecimento geral que o Movimento Indígena muito se destacou na luta pela garantia dos direitos destes povos durante o processo Constituinte de 1987. Diferentes mídias e a imprensa como um todo divulgaram incessantemente cenas de indígenas de várias etnias, que atuaram diretamente nas salas do Congresso Nacional, onde os seus destinos eram decididos por parlamentares membros das Comissões formadas durante os trabalhos da Assembleia Nacional Constituinte de 1987-1988.

\section{Desenvolvimentismo, Ambientalismo e Movimento Indígena: as vítimas do milagre ${ }^{1}$}

As incursões sobre as terras indígenas compõem uma temporalidade histórica de longuíssima duração, remete ao século XVI, à época das Grandes Navegações e dos "descobrimentos" do Novo Mundo. Contudo, o foco desta

\footnotetext{
${ }^{1}$ Referência à obra de mesmo título de Shelton H. Davis (1978).
} 
análise se situa no período mais recente, mais precisamente após o Golpe de 1964. Como precedente histórico, menciona-se a Marcha para o Oeste, que se iniciou oficialmente na Era Vargas, quando surgiram parques indígenas, semelhantes ao Parque Indígena do Xingu, criado em 1961 - cuja ideia foi lançada entre as décadas de 1940 e 1950, durante o processo de penetração territorial rumo ao interior do país - onde diferentes etnias foram misturadas sem se considerar a existência de grupos rivais entre as mesmas. Não sem a presença e a participação dos militares, foram criadas reservas indígenas que funcionaram como "estufa para que os grupos da região pudessem se aculturar paulatinamente." (SOUZA LIMA, 1990, p. 70).

No curso do período ditatorial a presença do Estado autoritário se tornou mais evidente mediante um projeto de governo no qual os índios foram tidos como verdadeiros empecilhos ao progresso, então em marcha. Todos os que apoiaram iniciativas de defesa dos índios enquanto grupos étnicos diferenciados foram vistos como opositores ao Regime. A política de integração nacional incentivou a criação das reservas indígenas, o que favoreceu a desintegração cultural dos índios e a liberação de suas terras originais para o desenvolvimento do país. Eram os anos do Brasil dos grandes projetos militares.

Somente no espaço da bacia amazônica, a partir de 1970, "o Governo brasileiro começou a construir várias estradas pioneiras” (DAVIS, 1978, p. 89), impulsionado por interesses economicistas e integracionistas em sua essência. Shelton Davis, no clássico Vítimas do milagre: O desenvolvimento e os índios no Brasil (1978), evidencia que os significativos conhecimentos técnicos dos batalhões do Exército; o ideal do projeto de integração da nação; as facilidades do governo militar em conseguir empréstimos estrangeiros para esta finalidade; além do aparato técnico estrangeiro disponibilizado exclusivamente para a “construção da rede rodoviária transamazônica” (DAVIS, 1978, p. 90), foram os motivadores primários desta grandiosa façanha desenvolvimentista, entretanto, extremamente questionável e condenável do ponto de vista ecológico, indígena e humano.

Diante deste quadro, Davis chama a atenção para a grave situação dos povos indígenas neste cenário de devastação humana, ambiental e cultural: 
De acordo com a FUNAI, havia mais de 5 mil índios vivendo na área dessas estradas, dispersos entre mais de 29 grupos tribais. Doze dessas tribos só tinham contatos esporádicos com a sociedade brasileira. Muitas outras eram hostis às intromissões externas e haviam conseguido expulsar estranhos. Duas das primeiras tribos a serem pacificadas pela FUNAI foram os Parakanân e os Kréen-Akaróre. É instrutivo considerar o que aconteceu com essas tribos em consequência da política da FUNAI e da construção das estradas (DAVIS, 1978, p. 93).

Os Kréen- Akaróre, como as 28 etnias devassadas pelo progresso, tiveram que deixar "seu santuário" (DAVIS, 1978, p. 98) para dar lugar à Rodovia Santarém-Cuiabá. O estado crítico a que foi submetido este povo foi explicitado nesta fala desesperada de Orlando Villas Boas:

Se uma reserva indígena não for demarcada imediatamente para os Kréen-Akaróre, e se uma política positiva de proteção não for desenvolvida em colaboração com os responsáveis pela construção da rodovia Santarém-Cuiabá, disse ele, então os Kréen-Akaróre, como tantas outras nações indígenas, desaparecerão inexoravelmente. Isso significará sua destruição final (VILLAS BOAS, Jornal do Brasil 1973 apud DAVIS, 1978, p. 99).

A Transamazônica - BR-230, que de estrada aberta floresta adentro correspondia a cerca de " 5 mil quilômetros de leste a oeste através da Amazônia, do Nordeste do Brasil à fronteira com o Peru" (DAVIS, 1978, p. 89) - é um desses grandes projetos, entre tantos, a atingir diretamente alguns povos indígenas da Amazônia, muitos ainda com pouco, ou sem nenhum contato com a comunidade nacional. Segundo Ribeiro (1990), esta obra faraônica da administração dos militares, projetada durante o Governo do presidente Emílio Garrastazu Médici (1969 a 1974), foi inaugurada antes de ser concluída em 1972, como parte do projeto que almejava integrar e controlar o território nacional a todo custo, mesmo que para isso centenas de índios fossem sacrificadas.

Para Gustavo Lins Ribeiro, esta foi, na verdade, uma característica dos grandes projetos militares: o caráter autoritário. O autoritarismo militar presente em uma política de realização de grandes projetos não vislumbra nenhuma alternativa de impedir danos irreversíveis para as comunidades locais e, muito menos, para o meio ambiente. 
O grande projeto implica, de um modo geral, uma inexistência de opções alternativas, numa desqualificação visível das populações locais enquanto sujeitas dos seus destinos. De fato, uma vez que a execução de um grande projeto esteja definida em altos níveis de poder político-econômico, a população local raramente, para não dizer nunca, tem voz ativa na necessidade de implantação ou não do projeto, ou no modo como ele vai ser executado (RIBEIRO, 1990, p. 88).

Essa assertiva explica o questionamento do índio Txibaibou-Bororo durante a realização do $2^{\mathrm{a}}$ Assembleia de Chefes Indígenas de 1975: “... Passar uma estrada em cima de uma aldeia é um crime. Por que não desviar. O Brasil é muito grande. Isso é triste” ( $2^{\mathrm{a}}$ ASSEMBLEIA DE CHEFES INDÍGENAS 1975, p. 41). Para os índios, que tiveram suas terras invadidas e viram muitos dos seus morrerem, não havia nenhuma coerência na lógica dos grandes projetos militares, mas, naquele contexto autoritário, os seus gritos não podiam ser ouvidos.

Os sinais de mudança dessa realidade vieram de fora, do contexto internacional favorável à luta pelos direitos humanos e civis das populações étnicas diferenciadas, com minorias e maiorias em vários países do mundo; além da luta engajada e do importante apoio dos ambientalistas na época, que viam não apenas as perdas humanas e culturais causadas pelas invasões das terras indígenas, mas também as perdas ambientais advindas da degradação da natureza e do desequilíbrio ecológico da mesma. Os resultados negativos que a construção da Transamazônica trouxe aos indígenas alcançaram as manchetes da imprensa internacional e afetou a imagem do Brasil no exterior.

A política econômica desenvolvimentista foi extremamente desastrosa ao meio ambiente e às populações indígenas, e seus resquícios podem ser sentidos ainda na atualidade, através dos grandes projetos do Plano de Aceleração da Economia (PAC), como a Usina de Belo Monte, a pavimentação da BR-319, as hidrovias dos Rios Madeira e Purus, entre tantos outros. Estes são alguns exemplos atuais de políticas governamentais que privilegiam o crescimento econômico a todo custo, sem considerar os desastres sociais e ambientais que as mesmas causaram e causarão ao meio ambiente, à biodiversidade de biomas como a Amazônia e o Cerrado e, principalmente, às populações tracionais e indígenas que dependem do equilíbrio ecológico para sobreviver (VERDUM, 2012). 
Nesta perspectiva, José Pimenta (2007) ressalta que a intensificação dos grandes projetos desenvolvimentistas na Amazônia, a partir da década de 1970, "traduziu-se pela destruição do meio ambiente e o etnocídio de muitos povos indígenas e já foi denunciada por uma vasta literatura” (PIMENTA, 2007, p. 635). A partir de 1980, diante de denúncias recorrentes junto a órgãos internacionais, como a Organização das Nações Unidas (ONU), contra os desmandos do governo, os ambientalistas do mundo todo voltaram a sua atenção para o Brasil, tornando-se atores sociais fundamentais na configuração dos movimentos sociais que personificaram uma ampla mobilização da sociedade civil. Assim,

Socializadas pouco a pouco nos mecanismos da política moderna, as lideranças indígenas passaram a articular suas reivindicações políticas e culturais à retórica ambientalista e estabeleceram novas parcerias. O poder simbólico, o exotismo e o carisma de algumas lideranças no campo interétnico também foram poderosos dinamizadores para interligar a questão indígena e a questão ambiental. $\mathrm{O}$ diálogo entre índios e ambientalistas criou um novo espaço político de alianças interculturais marcado pela manipulação de símbolos que servem, essencialmente, para alcançar objetivos pragmáticos. (PIMENTA, 2007, p. 636).

É importante ressaltar que em meados dos anos de 1970 algumas lideranças indígenas no Brasil começaram a sair de suas comunidades, rumo aos grandes centros, em busca de apoio para a causa indígena e expondo à sociedade civil uma realidade pouco conhecida, ou mesmo ignorada. Esses acontecimentos tiveram lugar durante os anos do então milagre econômico do Governo do General Emílio Garrastazu Médici (1969-1974).

Nesse período, em meio à censura e à repressão, quando vários temas foram proibidos à imprensa, a questão indígena apareceu como

[...] um dos poucos assuntos que era possível discutir sem correr riscos tão altos de represálias policiais quanto outros, como por exemplo, o movimento trabalhista. Muitos brancos se aproveitaram disso para ventilar suas próprias frustrações, enquanto os índios utilizaram esse espaço inesperado para expressar queixas centenárias (RAMOS, 1990, p. 118). 
Houve uma espécie de conspiração favorável à crença de que aqueles anos dariam lugar ao ápice do crescimento econômico do Brasil grande, e em proporções jamais vistas. Embalados por slogans do tipo "ninguém segura este país” e "pra frente Brasil", houve uma real impressão de que tudo estava indo bem, se não fossem a repressão, a tortura, a censura e os baixíssimos níveis de expectativa de vida da maioria da população, que, na verdade, viveu um verdadeiro desastre econômico.

De acordo com dados de Boris Fausto, "o governo contou com um grande avanço das telecomunicações no país, após 1964” (2000, p. 484). As facilidades de crédito levaram os aparelhos de televisão a mais de 40\% dos lares urbanos, sendo que em 1960 apenas 9,5\% possuíam o aparelho de TV. O Produto Interno Bruto (PIB) também cresceu anualmente numa média de 11,2\%, mas os empréstimos financeiros buscados em países desenvolvidos - que apresentaram ótimas oportunidades - também cresceram; assim como o comércio exterior, a fabricação de carros de porte médio, a exportação de produtos industriais e, claro, a dívida externa do país.

As consequências do milagre não tardaram a chegar: "excessiva dependência do sistema financeiro e do comércio internacional” e a desigualdade da "distribuição de renda" (FAUSTO, 2000, p. 487). Os ótimos indicadores do PIB demonstraram apenas que a economia estava crescendo, mas não indicaram que a população mais necessitada estivesse usufruindo desses resultados. Os problemas sociais e ambientais do país foram agravados em proporções desastrosas e a oposição às políticas do governo aumentou, com o surgimento de movimentos e guerrilhas no campo e na cidade.

Os indígenas, como a maioria da população, compunham o grupo dos excluídos da distribuição de renda do país; porém, mais que isso, foram atingidos diretamente pelos grandes projetos de integração nacional postos em execução pelo governo na época, como a Transamazônica, por exemplo, que foi inaugurada "em meio a críticas pela devastação do ambiente e pela invasão de terras indígenas" (FAUSTO, 2000, p. 574). A ocupação permanente dos territórios indígenas gerou um quadro de mobilizações que começou a ganhar expressividade no país, principalmente nos setores urbanos mais desenvolvidos, contando com o apoio de diversos setores da sociedade civil. 
Diante de todo o debate até aqui apresentado, pretende-se ressaltar o que pouco se observava quando Shelton H. Davis escreveu o seu livro clássico acima citado, qual seja, "os vínculos específicos entre a política de desenvolvimento do Governo brasileiro e as ameaças aos povos indígenas e ao meio ambiente" (1978, p. 17). A obra de Davis é do final da década de 1970, e apenas na década de 1980 as produções da História Ambiental começaram a se avolumar, logo, este debate estava em plena ascensão na Academia e fora dela, devido (entre tantos outros temas) ao quadro crítico da realidade atual sobre as problemáticas indígena e ambiental, em todos os cantos do planeta.

\section{Ensino de História e Educação Ambiental: povos indígenas em foco}

Diante do quadro apresentado linhas acima e das transformações socioeconômicas vivenciadas no Brasil a partir da década de 1950, quando as relações homem-natureza se metamorfosearam de maneira exorbitante e preocupante, surge também a necessidade de dar respostas aos problemas ambientais que se apresentavam de modo mais incisivo e alarmante; além de pensar como as questões ambientais são tratadas na escola e sob o olhar da História (Ambiental).

Ao se considerar a História uma lente através da qual se pode observar a ação do homem no tempo e as vicissitudes por ele provocadas na natureza, assim como as várias maneiras de também a natureza influenciar nas escolhas e ações do homem, procurou-se averiguar como os livros didáticos tratam (e se tratam) as degradações das terras indígenas e suas consequências traumáticas para o meio ambiente.

A preservação ambiental tem sido um tópico constante dos debates sobre meio ambiente e, conforme a produção historiográfica já identificou, não se trata de um problema apenas da atualidade. A intensificação e divulgação da necessidade de preservação são, no entanto, uma situação nova e se associa ao desenvolvimento da concepção de patrimônio cultural (BITTENCOURT, 2003, p. 57).

As dificuldades na orientação do alunado sobre a necessidade da preservação ambiental esbarra na própria concepção dos materiais didáticos, que apresentam limitações consideráveis em relação ao tema. As terras indígenas, apesar das constantes invasões, compreendem uma considerável 
parte das áreas de natureza preservadas, ao lado das Unidades de Conservação, Reserva Legal e Áreas de Preservação Permanente.

A inserção obrigatória do ensino de história e cultura indígena nos livros didáticos surge como "resultado de discussões, reivindicações e mobilizações dos povos indígenas, de indigenistas e de movimentos sociais engajados na defesa da causa. Em março de 2008, a Lei $n^{0}$ 11.645/2008 acrescentou a temática indígena ao artigo 26-A, já alterado, por sua vez, pela lei $n^{0} 10.639 / 2003$ " (SILVA, 2013, p. 125). Assim, essa Lei tornou obrigatório o ensino de história e cultura africana e afro-brasileira em todas as escolas de Educação Básica brasileiras, e a Lei 11.645, junto com essa temática, inclui também a questão indígena como conteúdo curricular obrigatório. Assim, ambas modificam

[...] a Lei de Diretrizes e Bases da Educação Nacional - LDBEN 9.394/96 - e se inserem em um movimento mais amplo, vivenciado pela sociedade brasileira atual, em prol da ampliação de direitos sociais e conquista de cidadania. Nesse sentido, desde a Constituição de 1988, passando pela referida LDBN, até a legislação mais recente, assiste-se a um progressivo reconhecimento, no plano formal, da necessidade do promover maior justiça social a partir da valorização e afirmação de culturas e identidades tradicionalmente negadas e silenciadas. (SILVA, 2013, p. 125).

Apesar dos avanços na legislação, a questão indígena ainda é comumente tratada nas escolas de forma estereotipada e folclórica, um exemplo claro são as representações que ainda são produzidas por estudantes do ensino básico sobre os povos indígenas, sedimentadas em uma tradição escolar que reforça certas distinções entre indígenas e não indígenas a partir de traços exteriores, popularizados nos livros didáticos, nas explanações orais de alguns professores e, principalmente, em uma data comemorativa tradicional nas escolas, o 19 de abril, o Dia do Índio.

Os livros didáticos ainda apresentam muitas limitações, como é perceptível na própria avaliação do PNLD da coleção Projeto Araribá 2 para o triênio 2011/2012/2013, quando mostra que, embora o tema seja abordado,

\footnotetext{
${ }^{2}$ Obra coletiva concebida, desenvolvida e organizada pela Editora Moderna, que tem como editora responsável a historiadora Maria Raquel Apolinário.
} 
seria necessária uma complementação por parte dos docentes 3 , pois a temática aparece vinculada "mais à historicização das situações que conduziram tais grupos a uma condição social de dificuldades no mundo contemporâneo do que, propriamente, à promoção positiva das representações referentes a tais grupos” (Guia de Livros Didáticos: PNLD 2011; História 2010, p. 87).

Ao analisar algumas obras da Coleção Projeto Araribá, dos anos finais do Ensino Fundamental, percebemos várias limitações nesse intercâmbio entre as questões ambiental, a história e a cultura indígena. O que existe é apenas uma manifestação quanto ao desmatamento ocorrido no século XVI, posto no do $7^{0}$ ano da coleção, como mostra a citação abaixo:

O primeiro produto explorado pelos portugueses em terras americanas foi o pau-brasil. Sua exploração foi declarada monopólio da Coroa, que a transferia a comerciantes portugueses em troca do pagamento de taxas.

O pau-brasil era adquirido por meio do escambo, uma relação comercial simples pela qual os portugueses forneciam produtos aos indígenas em troca do seu trabalho na exportação do paubrasil. Os indígenas cortavam a madeira e a transportavam até as caravelas portuguesas.

O primeiro desastre ecológico ocorrido em nossa terra foi o enorme desmatamento provocado pela retirada de toneladas de pau-brasil da Mata Atlântica (PROJETO ARARIBÁ HISTÓRIA, $7^{\circ}$ ano 2010, p. 166).

Nos próximos extratos da referida coleção fica evidente a existência de proposições no sentido de apontarem os indígenas, principalmente a partir das décadas de 1970 e 1980, como importantes interlocutores no que se refere à questão ambiental e à garantia de seu patrimônio territorial.

Acredita-se que a reetinização de muitos povos indígenas é favorecida pela existência de políticas públicas com programas sociais de transferência de renda para a população mais pobre, incluindo os índios, e a mobilização dos próprios indígenas, que se tornaram importantes interlocutores em debates sobre conservação ambiental, desenvolvimento sustentável e demarcação de terras (Projeto Araribá História, $8^{\circ}$ ano 2010, p. 254).

\footnotetext{
3 Sobre esta questão, a realidade escolar tem evidenciado uma espécie de círculo vicioso: o tema abordado de modo superficial no livro didático não é aprofundado pelos docentes da educação básica, que, na maioria das vezes, não são especialistas no assunto, portanto, sem as condições indispensáveis para fazer uma abordagem satisfatória.
} 
A violência contra os indígenas e o avanço sobre as suas terras prosseguiram após a independência do Brasil, com a expansão da lavoura cafeeira, a construção das vias férreas, a exploração de madeira e de minérios e a ampliação da fronteira agrícola. Mesmo assim, no século XXI, os povos indígenas ainda resistem. Segundo dados do Instituto Brasileiro de Geografia e Estatística (IBGE), atualmente existem cerca de 815 mil índios no Brasil, distribuídos em 230 povos. Eles vivem principalmente nas regiões Norte e Centro-Oeste do país, e, ainda hoje, algumas populações indígenas se mantêm isoladas do convívio com o restante da sociedade brasileira. Marcados por quinhentos anos de contato com os não índios, os povos indígenas lutam pelo direito às suas terras e para preservar suas tradições (Projeto Araribá História, $8^{\circ}$ ano, 2010, p. 11).

A Constituição de 1988, ao reconhecer também a necessidade de leis de proteção ambiental, o fim da censura às produções culturais e o direito dos povos indígenas às terras que ocupam, representou um enorme avanço para a democracia no país (PROJETO ARARIBÁ HISTÓRIA, $9^{\circ}$ ano 2010, p. 220).

A historiadora Circe Bittencourt (1997), em uma análise voltada para textos e imagens nos livros didáticos, nos lembra que,

O livro didático tem sido, desde o século XIX, o principal instrumento de trabalho de professores e alunos, sendo utilizado nas mais variadas salas de aulas e condições pedagógicas, servindo como mediador entre a proposta oficial do poder expressa nos programas curriculares e o conhecimento escolar ensinado pelo professor. (BITTENCOURT, 1997, p. 7273).

A autora chama a atenção, entre outros aspectos de sua natureza, para o fato de que autores e editores costumam simplificar questões complexas, padronizando-as e impedindo reflexões acerca dos temas abordados, ressaltando também seu caráter "limitado e condicionado por razões econômicas, ideológicas e técnicas” (BITTENCOURT, 1997, p. 73). Apesar do importante papel que o livro didático possui, cabe ao professor fazer a mediação no processo ensino/aprendizagem, consciente de que o livro é um instrumento de reprodução ideológica e de um saber oficial. Nesse sentido, percebe-se a importância de se ter nesse processo professores bem preparados, críticos e conscientes de seu papel.

A percepção que se tem nos livros didáticos aqui analisados é a de que procuram explicar, mesmo que de forma pouco aprofundada, que as terras indígenas representam mais que um meio de subsistência, indicando que elas 
estão ligadas à cosmologia destes povos e são necessárias para garantir o modo de vida tradicional dos mesmos.

A terra não representa apenas o meio de subsistência para as populações indígenas. Ela está ligada às crenças, aos costumes, aos hábitos e às trocas sociais dos povos indígenas. Por essas razões, para garantir o modo de vida tradicional desses grupos, os sucessivos governos brasileiros têm trabalhado para demarcar as terras indígenas tradicionalmente ocupadas por grupos indígenas (PROJETO ARARIBÁ HISTÓRIA, $9^{\circ}$ ano 2010, p. 254).

A necessidade e a morosidade da demarcação destas terras no Brasil, assim como as constantes invasões das fronteiras dos territórios indígenas pelo não índio, são enfatizadas nesses livros didáticos como um dos maiores problemas que os povos indígenas enfrentam na atualidade.

A demarcação é um recurso que garante a posse e o uso da terra pelas populações indígenas, protegendo, assim, a cultura e a identidade delas. Esse instrumento administrativo também é um reconhecimento público de nossa dívida histórica com os indígenas, que ao longo de 500 anos foram sendo sistematicamente expulsos de suas terras e confinados em pequenos territórios.

Segundos dados do Instituto Socioambiental, até 2012, cerca de 100 milhões de hectares já haviam sido demarcados na Amazônia Legal, o que corresponde a cerca de $21,73 \%$ de sua extensão. Porém, apesar das garantias legais, o direito dos povos indígenas à terra é constantemente ameaçado: agricultores, pecuaristas, madeireiras e mineradoras desrespeitam os limites das terras indígenas, muitas vezes de forma violenta, e infringem um importante direito dessas populações. (PROJETO ARARIBÁ HISTÓRIA, $9^{\circ}$ ano 2010, p. 254).

No entanto, não se percebe, nos livros analisados, uma investigação problematizada dos transtornos ocasionados pela invasão dos territórios indígenas. A ação de mineradores e garimpeiros, entre outros, em territórios indígenas, que são promovidos em grande parte à margem da lei, tem promovido malefícios imensuráveis aos povos indígenas, que presenciam de tempos em tempos o esvaziamento de recursos naturais fundamentais para a sua existência física e cultural. De acordo com Pedro Colaneri Abi-Eçab (2011, p. 3), "Mesmo no caso da mineração, cujos empreendimentos são licenciados, é de 
se ressaltar a influência do lobby minerário, facilitando por meio de injunções políticas a autorização de empreendimentos de duvidosa sustentabilidade”. O autor assinala ainda que, embora o usufruto dos indígenas não abarque a garimpagem nem a faiscação,

[...] dependendo-se o caso, devendo ser obtida a permissão da lavra garimpeira, conforme já decidiu o STF, as lideranças indígenas tem se aliado a garimpeiros em inúmeros casos, "arrendando" as terras para a atividade, em que pese alguns honrosos casos de resistência indígena a esta dilapidação do patrimônio ambiental (ABI-EÇAB, 2011, p. 3).

Os livros didáticos, em sua grande maioria, não apresentam essas problemáticas ou alternativas para superar as dificuldades inerentes às associações prejudiciais dos indígenas com mineradores, garimpeiros e regionais, nem sempre bem intencionados, além das constantes invasões promovidas por não indígenas. No livro do $9^{\circ}$ ano, porém, aparece como opção, o que afirma ser iniciativa de participantes do movimento indígena, a proposta de transformação das Terras Indígenas em Distritos Especiais Indígenas, com autonomia orçamentária e administrativa.

Para superar esses problemas, muitos movimentos indígenas vêm apresentando propostas concretas de mudanças, como a transformação das Terras Indígenas em Distritos Especiais Indígenas, com autonomia orçamentária e administrativa. Os indígenas também reivindicam capacitação política e técnica para lidar com os desafios que a gestão de suas próprias terras pode trazer, como conciliar os interesses de diferentes povos indígenas e estabelecer relações produtivas e justas com os não índios. (PROJETO ARARIBÁ HISTÓRIA, $9^{\circ}$ ano 2010, p. 254).

Trata-se de uma proposta concreta de mudança apresentada por muitos movimentos indígenas, visando, desta forma, conciliar os interesses dos povos indígenas e estabelecer relações mais juntas e produtivas com não indígenas. Outra questão ligada à educação ambiental 4 e não contemplada nos livros

\footnotetext{
4 O conceito de Educação Ambiental é oriundo da Lei 9.795/99, que impõe sua obrigatoriedade no ensino formal. Conforme o art. $1^{\circ}$ da Lei 9.795/99 do Capítulo I, intitulado Da Educação Ambiental, entende-se por Educação Ambiental em seu Art. $1^{\mathrm{o}}$ "os processos por meio dos quais o indivíduo e a coletividade constroem valores sociais, conhecimentos, habilidades, atitudes e competências voltadas para a conservação do meio ambiente, bem de uso comum do povo,
} 
didáticos de modo eficiente, que convêm ressaltar, é que os povos indígenas vêm enfrentando novos problemas ambientais oriundos do contato com a população exógena, como o acúmulo de lixo, originário do consumo de produtos industrializados de difícil decomposição na natureza (como plásticos, metais etc.) que, na maioria das vezes, não são descartados corretamente.

Na ausência (ou ineficiência) de um sistema de coleta do lixo (normal ou seletiva), estes detritos são alocados nas proximidades das moradias, levando à poluição do solo e dos rios dos territórios indígenas, como se observou in loco, na aldeia Porteira, do povo indígena Akwê-Xerente, no estado do Tocantins, em visita realizada em 2016. A solução de situações como essas tem inquietado alguns povos indígenas, e é um tema não tratado nos livros didáticos e ignorado por muitos estudantes, inclusive universitários.

Sabe-se que o espaço de informação e discussão dos livros didáticos é extremamente limitado, e que não se pode esperar que o mesmo aborde temas como o aqui apresentado com grande atenção. No entanto, é importante ressaltar que a temática ambiental está inserida nos projetos educacionais do MEC, através dos atuais Parâmetros Curriculares Nacionais (PCNs), que classifica o Meio Ambiente como um tema transversal a ser trabalhado na sala de aula. De maneira isolada, o tema ambiental é tratado no livro didático de história Projeto Araribá, $9^{\circ}$ ano, na Unidade Desafios do Novo Milênio, mas neste tópico os indígenas não são mencionados uma só vez, o que seria uma ótima oportunidade para trabalhar a interdisciplinaridade que o tema requer.

Embora a História Ambiental ainda não tenha recebido um espaço significativo nos livros didáticos - apesar da obrigatoriedade da legislação -, é no campo do ensino que ela pode ter um grande potencial e se apresentar como um importante dispositivo, aliada à preservação do meio ambiente. Apesar do reconhecimento das dificuldades logísticas para se fazer um bom trabalho com esta temática em sala de aula, alguns avanços podem ser pontuados para além das tentativas de inseri-la no livro didático, como o fato de já ser possível encontrar algumas publicações voltadas diretamente para a educação ambiental, como o texto do educador Carlos Carola (2009), no qual ele afirma que, 
Para ensinar e fazer História Ambiental, o professor deve apenas seguir as premissas básicas do bom educador: estudar e pesquisar; assimilar e problematizar conceitos; manter-se atualizado por meio de leituras e participação em eventos e, principalmente, procurar desenvolver projetos de pesquisa visando conhecer a história da sua escola, comunidade ou país relacionada ao ambiente natural. (CAROLA, 2009, p. 178).

Apesar dos avanços, reconhecem-se as dificuldades de se colocar em prática o que sugere o autor, tanto quanto às premissas básicas de um bom professor, quanto à prática de trabalhos interdisciplinares na sala de aula, uma vez que a escola é, ainda hoje, "uma instituição na qual o legado de uma formação compartimentada tem solidamente criado uma tradição" (BITTENCOURT, 2003, p. 52). E, sabe-se, uma das características da História Ambiental é, justamente, a interdisciplinaridade. Nessa perspectiva, o tema discutido neste artigo se torna bastante propositivo, no sentido de que as escolas (especialmente os professores de História) possam aqui perceber um canal importante para se discutir a temática ambiental, debruçando-se sobre a longa trajetória indígena de luta pela sobrevivência e preservação de suas terras e de suas culturas.

\section{Considerações finais}

A interferência no meio ambiente, que comprometeu direta e/ou indiretamente a cultura e a vida dos povos indígenas, ocasionada pela expansão colonial dos séculos XVII e XVIII, e, principalmente, no século XIX, não é trabalhada de forma abrangente nos livros didáticos. Mais que isso, a temática indígena, no que tange ao meio ambiente, possui um espaço demasiadamente limitado nestas temporalidades. Na atualidade, o Brasil se encontra em pleno processo de desenvolvimento econômico, sendo assim, como em um passado não muito distante, vislumbra-se a execução de grandes projetos de infraestrutura, que, inevitavelmente, promovem grandes impactos ambientais e injustiças socioculturais às populações tradicionais.

As populações indígenas, mais uma vez, enfrentam, como no passado, problemas oriundos da construção de hidrelétricas, construção de rodovias e hidrovias, aterros sanitários, construção de ferrovias, entre outros. Somam-se a 
essas outras ameaças ao meio ambiente em terras indígenas (muitas delas ausentes nos livros didáticos) apontadas por Abi-Eçab (2011), como: assentamentos de reformas agrárias; extração de madeiras; arrendamentos de terras indígenas e parcerias agropecuárias; agrotóxicos; transgênicos; espécies exóticas invasoras, uso do fogo; biopirataria; fragmentação de áreas; sobre caça e a monocultura.

Em síntese, as terras indígenas são hoje uma das mais importantes formas de preservação do meio ambiente no território nacional. Imagens de satélite demonstram claramente que estas terras são as mais preservadas da Amazônia Legal. Logo, se o livro didático não pode abarcar tantos temas importantes e relevantes para a sobrevivência de todas as espécies, de maneira satisfatória, os professores e alunos podem e devem buscar outros meios de juntos entrecruzarem estes conhecimentos; e, assim, compreenderem que educação ambiental é fundamental para as gerações futuras e para a continuidade da vida, do meio ambiente e das culturas, seja da espécie humana e animal, seja da natureza, dos indígenas e de suas culturas.

\section{Referências}

$2^{\text {a }}$ ASSEMBLEIA DE CHEFES INDÍGENAS. Missão Cururu. Cópia de documento datilografado/CIMI - Setor de documentação), Pará, 8-4 de maio de 1975 .

BRASIL. MINISTÉRIO DA EDUCAÇÃO. Parâmetros curriculares nacionais. Brasília: DF: MEC/SEF, 1998.

ABI-EÇAB, Pedro Colaneri. Principais ameaças ao meio ambiente em terras indígenas. Planeta Amazônia. Revista Internacional de Direito Ambiental e Políticas Públicas. Amapá, 2011. Disponível em:

file://C:/Users/Cliete/Desktop/551-2028-1-PB.pdf; Acesso em 17/12/2014.

BICALHO, Poliene Soares dos Santos. Protagonismo Indígena no Brasil: Movimento, Cidadania e Direitos (1970-2009) Brasil. Tese. Brasília: Universidade de Brasília, 2010.

BITTENCOURT, Circe Maria Fernandes. Meio Ambiente e Ensino de História. Revista História \& Ensino. Londrina, n. 9, pp. 63-69, /out. 2003.

Paulo: Contexto, 1997. 
Revista Brasileira de História \& Ciências Sociais - RBHCS

Vol. $12 \mathrm{~N}^{\circ} 23$, Janeiro - Junho de 2020

BRASIL. Ministério da Educação. Guia de livros didáticos: PNLD 2011: História: ensino fundamental: anos finais. Brasília: Ministério da Educação, Secretaria de Educação Básica, 2010.

CAROLA, Carlos Renato. Meio Ambiente. In: PINSKY, Carla Bassanezi: Novos Temas nas Aulas de História. São Paulo: Contexto, 2009, pp. 173-200.

DAVIS, Shelton H. Vítimas do Milagre: O Desenvolvimento e os Índios do Brasil. Rio de Janeiro: Zahar Editores, 1978.

GOHN, Maria da Gloria. Teorias dos Movimentos Sociais. Paradigmas clássicos e contemporâneos. São Paulo: Loyola, 1997.

GOMES, Mércio Pereira. Os Índios e o Brasil. Ensaio Sobre um holocausto e sobre uma nova possibilidade de convivência. Petrópolis: Vozes, 1988.

FRANCO, José Luiz de Andrade. A. Prefácio. In: PIETRAFESA. José Paulo. SILVA, S. D. (Orgs.). Transformações no Cerrado. Progresso, consumo e natureza. Goiânia: Ed. PUC/Goiás, 2011, pp. 11-12.

FAUSTO, Boris. História do Brasil. 8. ed. São Paulo: Ed. Edusp, 2000.

KRENAK, Ailton. Ideias para adiar o fim do mundo. 1 ed. São Paulo: Companhia das Letras, 2019.

LACERDA, Rosane. Os Povos Indígenas e a Constituinte - 1987/1988. Brasília: Conselho Indigenista Missionário (CIMI), 2008.

LEITÃO, Sergio. Direitos Indígenas. Debate com Dalmo Dallari, Sérgio Leitão, Paulo de Bessa Antunes e Paulo Monteiro. In: Novos Estudos CEBRAP. São Paulo, n. 69, jul. 2004.

MARTINEZ, Paulo Henrique. História Ambiental no Brasil. Pesquisa e ensino. São Paulo: Cortez, 2006.

MINISTÉRIO da Educação. Guia de Livros Didáticos: PNLD. História: ensino fundamental: anos finais. Brasília: Ministério da Educação. Secretaria de Educação Básica, 2010.

PIMENTA, José. Indigenismo e ambientalismo na Amazônia ocidental: a propósito dos Ashaninka do rio Amônia. Revista de Antropologia, n. 50 (2), pp. 634-681, 2007.

PROJETO ARARIBÁ: História/organizadora Editora Moderna. Obra coletiva concebida, desenvolvida e produzida pela Editora Moderna; editora responsável Maria Raquel Apolinário, $6^{\circ}$ ano. 3 ed. - São Paulo: Moderna, 2010.

PROJETO ARARIBÁ: História/organizadora Editora Moderna. Obra coletiva concebida, desenvolvida e produzida pela Editora Moderna; editora responsável Maria Raquel Apolinário, $9^{\circ}$ ano. 3 ed. - São Paulo: Moderna, 2010. 
RAMOS, Alcida Rita. Vozes Indígenas: O Contato Vivido e Contado. Anuário Antropológico, n. 87. Tempo Brasileiro, pp. 117-143, 1990.

RIBEIRO, Gustavo Lins. Militares, Antropologia, Desenvolvimento. In: OLIVEIRA FILHO, João Pacheco (ed). Projeto Calha Norte. Militares, Índios e Fronteiras: Antropologia e Indigenismo. UFRJ: PETI/Ed., p. 87-96 1990.

SANTOS, Boaventura de Sousa. Pela Mão de Alice: o social e o político na pós-modernidade. $10^{\mathrm{a}}$ ed. São Paulo: Cortez, 2005.

SILVA, Araci Lopes da. (Org.). A Questão Indígena na Escola: Subsídios Para Professores de $1^{0}$ e $2^{0}$ Graus. São Paulo: Brasiliense, 1987.

SILVA, Ana Cláudia Oliveira da. A implantação da Lei 11.645/2008 no Brasil: Um Histórico de Mobilizações e Conquistas. In: SILVA, Edson; SILVA, Maria da Penha da (Orgs.). A Temática Indígena Na Sala De Aula: Reflexões para o ensino a partir da Lei 11.645/2008. Ed. Universitária da UFPE, p. 125, 2013.

SOUZA LIMA, Antônio Carlos de. Indigenismo e geopolítica. Projetos militares para os índios no Brasil. In: OLIVEIRA FILHO, João Pacheco (Orgs.): Projeto Calha Norte. Militares, Índios e Fronteiras: Antropologia E Indigenismo: Rio de Janeiro: PETI/Ed. UFRJ, pp. 60-86, 1990.

TXIBAIBOU (Bororo). In: $2^{\text {a }}$ ASSEMBLEIA DE CHEFES INDÍGENAS. Missão Cururu, Pará, 8-14 de maio de 1975.

VERDUM, Ricardo. As obras de infraestrutura do PAC e os Povos Indígenas na Amazônia brasileira. Observatório de investimento na Amazônia. INESC, 2012.

(http://www.inesc.org.br/biblioteca/noticias/biblioteca/textos/obras-do-pac-epovos-indigenas/; Acesso em 18/12/2014)

WORSTER, Donald. Para Fazer História Ambiental. Estudos Históricos, n. 4, v. 8, p.198-215, 1991. 